\title{
PENGARUH JENIS BAHAN TERHADAP PROSES GASIFIKASI SAMPAH ORGANIK MENGGUNAKAN UPDRAFT FIXED BED REACTOR
}

\author{
${ }^{(1 *)}$ Wira Widyawidura, ${ }^{(2)}$ Ratih Puspita Liestiono, ${ }^{(2)}$ Muhammad Sigit Cahyono, \\ ${ }^{(3)}$ Agus Prasetya, ${ }^{(4)}$ Mochammad Syamsiro \\ ${ }^{(1)}$ Program Studi Teknik Lingkungan, Fakultas Teknik, Universitas Proklamasi 45 \\ ${ }^{(2)}$ Program Studi Teknik Perminyakan, Fakultas Teknik, Universitas Proklamasi 45 \\ ${ }^{(3)}$ Departemen Teknik Kimia, Fakultas Teknik, Universitas Gadjah Mada \\ ${ }^{(4)}$ Jurusan Teknik Mesin, Fakultas Teknik, Universitas Janabadra \\ *Email korespondensi : wirawidura@gmail.com \\ Jl.Proklamasi No.1 Babarsari Yogyakarta
}

\begin{abstract}
Organic wastes has potential as a renewable energy resource. The waste could be converted as a gaseous fuel through gasification method. The objective of this reserach was to study the performance of gasification of various organic waste using fixed bed updraft gasifier especially in term of production of heat and stability of gas production. The raw material that used are rice husk, sawdust pellet, and wood branch. The stabilization of gas production was measurdd based on the time interval of gas could be burnt. The result shows that the kind of biomass has influenced the heating rate and stability of gas production. Sawdust pellet have the biggest burning stabilisation, that is 45 minute of burning time, compare to rice husk that have 15 minute burning time, and wood branch that have 30 minutes burning time. The main problem of gasification of organic waste was less stabilization of gas production due to low material compaction and uncontinuous mass flow.
\end{abstract}

Keywords: gasification, bagasse, downdraft gasifier, performance

\section{PENDAHULUAN}

Salah satu energi alternatif yang sekarang sedang dikembangkan adalah energi yang berasal dari bahan - bahan organik, hal ini dikarenakan senyawa organik tersebut tergolong energi yang dapat diperbarui. Keberadaaan bahan bahan organik tersebut mudah didapat dan terjamin kontinuitasnya, selain itu yang terpenting bahan - bahan organik tersebut ramah lingkungan. Hal ini yang menjadi faktor utama keberadaan bahan - bahan organik dipertimbangkan sebagai energi masa depan dalam rangka mewujudkan teknologi hijau (Sutanto, dkk. 2015)

Menurut Cahyono (2013), Indonesia memiliki ketersediaan bahan organik berupa sisa pertanian dan perkebunan yang berlimpah. Beberapa contohnya adalah potongan kayu, ranting, daun, sekam padi, ampas tebu, cangkang dan tandan kosong sawit, serbuk kayu, serta sabut dan cangkang kelapa. Selain itu, sampah organik dari pemukiman merupakan potensi besar lainnya yang juga amat melimpah.

Menurut Hidayat (2013), salah satu teknologi potensial untuk pemanfaatan sampah organik adalah teknologi gasifikasi. Gasifikasi bertujuan untuk mengkonversi bahan bakar cair maupun padat menjadi flammable gas menggunakan suatu reaktor yang disebut gasifier.

Gasifier adalah istilah untuk reaktor yang memproduksi gas dengan cara pembakaran tidak sempurna (oksidasi sebagian) bahan bakar biomasa. Ketika gasifikasi berlangsung, terjadi kontak antara bahan bakar dengan medium penggasifikasi di dalam gasifier. Suatu sistem gasifikasi terdiri atas reaktor gasifikasi yang dilengkapi alat-alat untuk 
pengkondisian bahan bakar dan producer gas. Dari semua jenis gasifier yang ada, reaktor tipe Updraft merupakan reaktor yang paling sederhana dan mudah diaplikasikan di masyarakat sebagai pengganti gas LPG untuk kebutuhan memasak sehari-hari. Unit gasifikasi biomassa tipe Updraft diharapkan dapat membantu masyarakat dalam pemenuhan kebutuhan energi alternatif. Akan tetapi, setiap unit gasifikasi memiliki karakteristik-karakteristik tertentu bergantung pada umpan biomassa yang berpengaruh terhadap kinerja unit tersebut sehingga diperlukan pengujian alat agar dapat diketahui kondisi operasi terbaiknya. Oleh karena itu, tujuan dari penelitian ini adalah untuk mengetahui jenis bahan terhadap kinerja proses gasifikasi sampah organik menggunakan updraft fixed bed gasifier.

\section{LANDASAN TEORI}

\section{A. Sampah Organik}

Sampah adalah sisa dari segala barang yang sudah tidak dimanfaatkan lagi oleh manusia. Masyarakat mengenal jenis sampah organik dan sampah anorganik. Sampah organik adalah jenis sampah yang mudah untuk didaur ulang karena alam dapat langsung menguraikan senyawa-senyawa yang terkandung dalam sampah tersebut. Sampah anorganik merupakan sampah hasil dari proses industri yang pada umumnya kurang bersahabat karena proses penguraian sampah membutuhkan waktu yang lama bahkan kadang tidak dapat diurai sama sekali sebelum dilakukan perlakuan khusus.

Sampah organik telah menjadi permasalahan bagi masyarakat dan pemerintah, diantaranya timbulnya pencemaran lingkungan. Laju dekomposisi sampah jenis ini sangat bergantung pada struktur molekul penyusunnya. Jadi sampah organik padat ada yang dapat terurai secara cepat dan ada yang lebih lama. Sumber, komposisi dan karakteristik sampah merupakan hal yang terpenting dalam memilih teknologi pengolahan sampah. Apabila sampah tersebut dibiarkan menumpuk atau tidak diolah menjadi produk yang bermanfaat, akan timbul berbagai masalah, di antaranya bau busuk yang disebabkan oleh adanya kegiatan mikro organisme. Di sisi lain, sampah organik yang membusuk juga dapat mengakibatkan berkembangnya berbagai macam bibit penyakit.

(http://repository.ipb.ac.id/jspui/bitstream/ 123456789/40580/3/BAB\%20II_2007aga3.pdf).

\section{B. Gasifikasi}

Gasifikasi adalah suatu teknologi proses konversi bahan padat menjadi gas yang mudah terbakar. Bahan padat yang dimaksud misalnya, biomasa, batubara, dan arang, sedangkan gas yang dimaksud seperti $\mathrm{CO}, \mathrm{H}_{2}$, dan $\mathrm{CH}_{4}$. Proses gasifikasi terdiri dari empat tahapan proses atas dasar perbedaan rentang temperatur, yaitu pengeringan $\left(\mathrm{T}>150^{\circ} \mathrm{C}\right)$, pirolisis $(150$ $\left.<\mathrm{T}<700^{\circ} \mathrm{C}\right)$, oksidasi $\left(700<\mathrm{T}<1500^{\circ} \mathrm{C}\right)$, dan reduksi $\left(800<\mathrm{T}<1000^{\circ} \mathrm{C}\right)$. Proses pengeringan, pirolisis, dan reduksi bersifat menyerap panas (endotermik), sedangkan proses oksidasi bersifat melepas panas (eksotermik). Panas yang dihasilkan dalam proses oksidasi digunakan dalam proses pengeringan, pirolisis dan reduksi. Bahan kering hasil dari proses pengeringan mengalami proses pirolisis, yaitu pemisahan volatile matters (uap air, cairan organik, dan gas yang tidak terkondensasi) dari arang. Hasil pirolisis berupa arang mengalami proses pembakaran dan proses reduksi yang 
menghasilkan gas produser yaitu, $\mathrm{H}_{2}$ dan CO (Pranolo, 2010).

Menurut Higman, 2003, terdapat dua tipe utama gasifier yakni tipe fluidized bed dan tipe fixed bed,. Jika ditinjau dari arah aliran udara, fixed bed gasifier dibagi menjadi tiga tipe, yakni downdraft, updraft, dan crossdraft. Pada penelitian ini, digunakan fixed bed gasifier tipe updraft karena kemungkinan hilang tekannya sangat rendah, efisiensi panasnya bagus, dan kecenderungan membentuk terak sedikit. Selain itu, tipe ini sangat sederhana operasionalnya sehingga mudah digunakan di masyarakat.

Pada gasifier terdapat empat zona utama yang di dalamnya terjadi proses gasifikasi yaitu proses pengeringan bahan bakar, pirolisis, pembakaran, dan reduksi. Meskipun terdapat zona yang prosesnya tumpang tindih, masing-masing proses dapat diasumsikan menempati zona yang terpisah dimana reaksi kimia dan panas berbeda. Zona-zona tersebuut pada gasifier tipe updraft fixed bed dapat dilihat dalam Gambar 1 berikut.

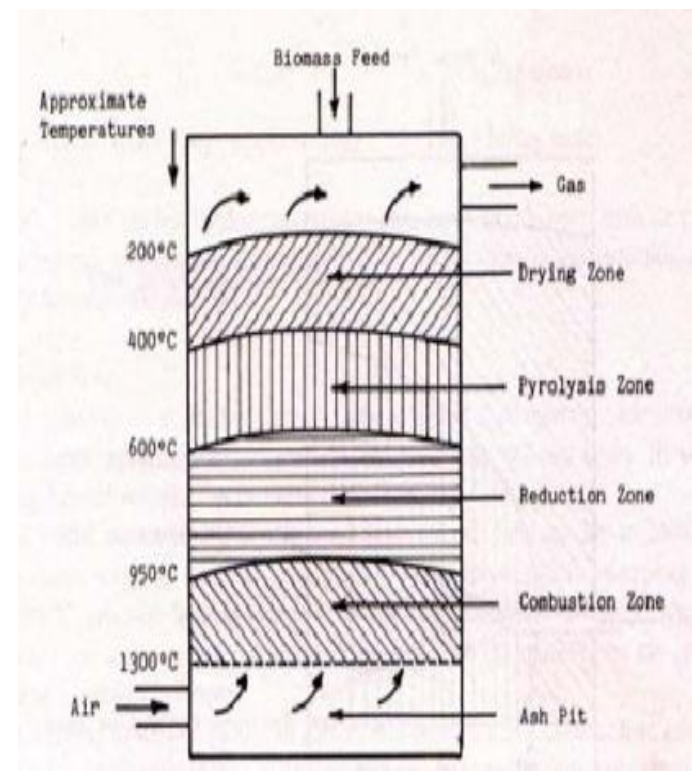

Gambar 1. Gasifier tipe updraft

\section{METODE PENELITIAN}

\section{A. Alat Penelitian}

Peralatan gasifikasi yang digunakan dalam penelitian ini ditunjukkan pada gambar 2. Gasifier ini merupakan sebuah silinder yang terbuat dari bahan stailess steel dengan diameter $40 \mathrm{~cm}$, tinggi 100 $\mathrm{cm}$ dan ketebalan $4 \mathrm{~mm}$, yang berfungsi sebagai tempat terjadinnya proses gasifikasi.

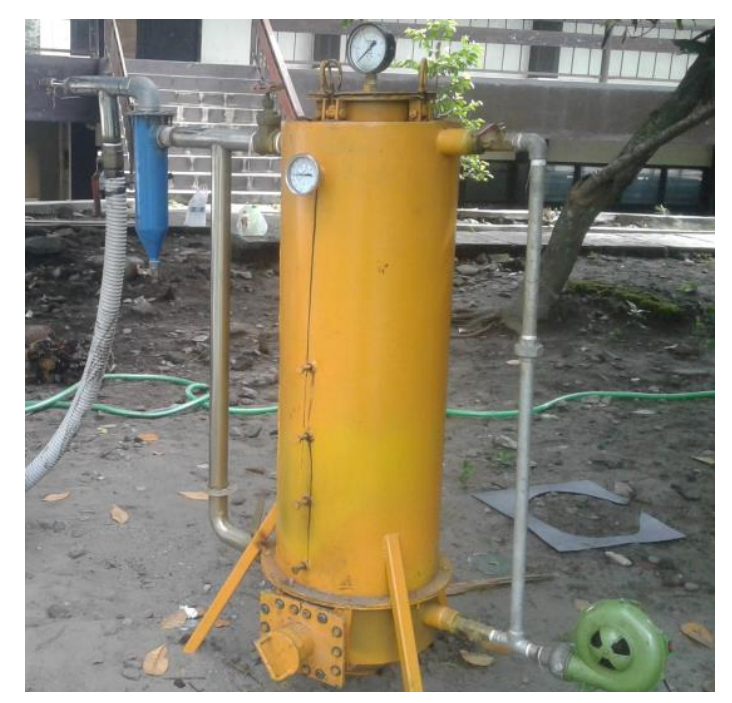

Gambar 2. Alat penelitian gasifikasi sampah organik

\section{B. Bahan Penelitian}

Bahan yang digunakan dalam penelitian ini adalah sampah organik berupa sekam padi, pelet serbuk gergaji, serta daun dan ranting tanaman pinus yang didapatkan dari lahan di skeitar hutan pinus Dlingo, Kabupaten Bantul. Bahan baku berupa sampah organik ini sebelum digunakan, dikeringkan terlebih dahulu dengan cara dijemur di terik matahari selama satu hari. Setelah kering, sebagian bahan diambil untuk dianalisa kandungan proximate, sedangkan sisanya diproses gasifikasi. 


\section{Jalannya Penelitian}

- Tahap pertama dari penelitian adalah penyiapan alat gasifikasi (Gasifier).

- Pada bagian sisi gasifier dibuat 4 buah saluran thermokopel type $\mathrm{K}$ (cromnelAlumnel) berbaris vertikal dengan jarak $5 \mathrm{~cm}, 20 \mathrm{~cm}, 35 \mathrm{~cm}$, dan $50 \mathrm{~cm}$ dari grate untuk menentukan area gasifikasi.

- Udara pembakaran dialirkan menggunakan sebuah blower dengan kapasitas $1.000 \mathrm{lpm}$. Kecepatan udara masuk divariasikan sesuai variabel AirFuel ratio. Setiap variabel, dilakukan proses gasifikasi selama 1 jam.

- Rangkaian peralatan yang telah tersedia diujicoba terlebih dahulu tanpa menggunakan beban untuk mengetahui apakah peralatan berfungsi dengan baik atau tidak. Apabila ada bagian peralatan yang tidak berfungsi dengan baik, akan diperbaiki. Apabila semua bagian berfungsi normal, maka penelitian akan dilanjutkan.

- Tahapan pengambilan data dimulai dengan membuka penutup reaktor dan memasukkan $5 \mathrm{~kg}$ bahan sampah organik berupa daun seluruhnya $(100 \%)$, sementara di bagian bawah dimasukkan sedikit ranting dan daun yang mudah terbakar pemantik awal.

- Pemantik awal dinyalakan kemudian blower dihidupkan. Api yang berasal dari bagian bawah reaktor akan memanaskan bahan yang ada di dalam reaktor sehingga terjadi proses oksidasi, reduksi, pirolisis, dan pengeringan. Sementara suhu reaktor mulai dicatat sejak blower dinyalakan setiap 10 menit sampai satu jam.

- Proses gasifikasi dilakukan sampai muncul gas yang keluar melalui pipa keluaran gas, lalu dipantik hingga menyalakan api yang stabil. Saat api telah stabil, gas diambil menggunakan syringe untuk diuji di laboratorium.
- Langkah percobaan diulangi untuk variabel jenis bahan yang berbeda.

- Setelah selesai, char dan ash dikeluarkan lalu ditimbang massanya. semua peralatan dirapikan kembali.

\section{HASIL DAN PEMBAHASAN}

\section{A. Distribusi Suhu Reaktor}

Pengukuran suhu sepanjang pengujian, dilakukan menggunakan peralatan berupa termokopel tipe-K pada 3 titik reaktor dengan ketinggian dari dasar yang berbeda. Pembacaan suhu tersebut dilakukan setiap 15 menit, mulai penyalaan bahan baku hingga pengujian berakhir, yaitu sekitar satu jam. Setiap saat pengambilan data suhu, dilakukan percobaan penyalaan gas hasil gasifikasi, dimana waktu yang dibutuhkan setelah mulai penyalaan sampai didapatkan gas yang bisa terbakar secara kontinyu adalah waktu pengeringan bahan untuk melepaskan air yang terkandung di dalam bahan tersebut. Pada percobaan gasifikasi dengan beberapa macam bahan baku ini, didapatkan hasil bahwa waktu pengeringan masing-masing bahan berbeda, dimana bahan bakar pelet serbuk gergaji lebih cepat menghasilkan gas yang mudah terbakar, hanya dalam waktu 15 menit. Sedangkan untuk bahan bakar campuran ranting kayu membutuhkan waktu 30 menit, dan bahan baku sekam padi membutuhkan waktu pengeringan sekitar 45 menit, yang ditunjukkan dengan terbakarnya gas hasil gasifikasi. Distribusi suhu hasil pengujian gasifikasi untuk masing-masing jenis bahan bakar ditunjukkan pada gambar 3 berikut.

Sedangkan distribusi suhu hasil pengujian gasifikasi untuk masing-masing jenis bahan bakar ditunjukkan pada gambar 3, 4, dan 5 berikut . 


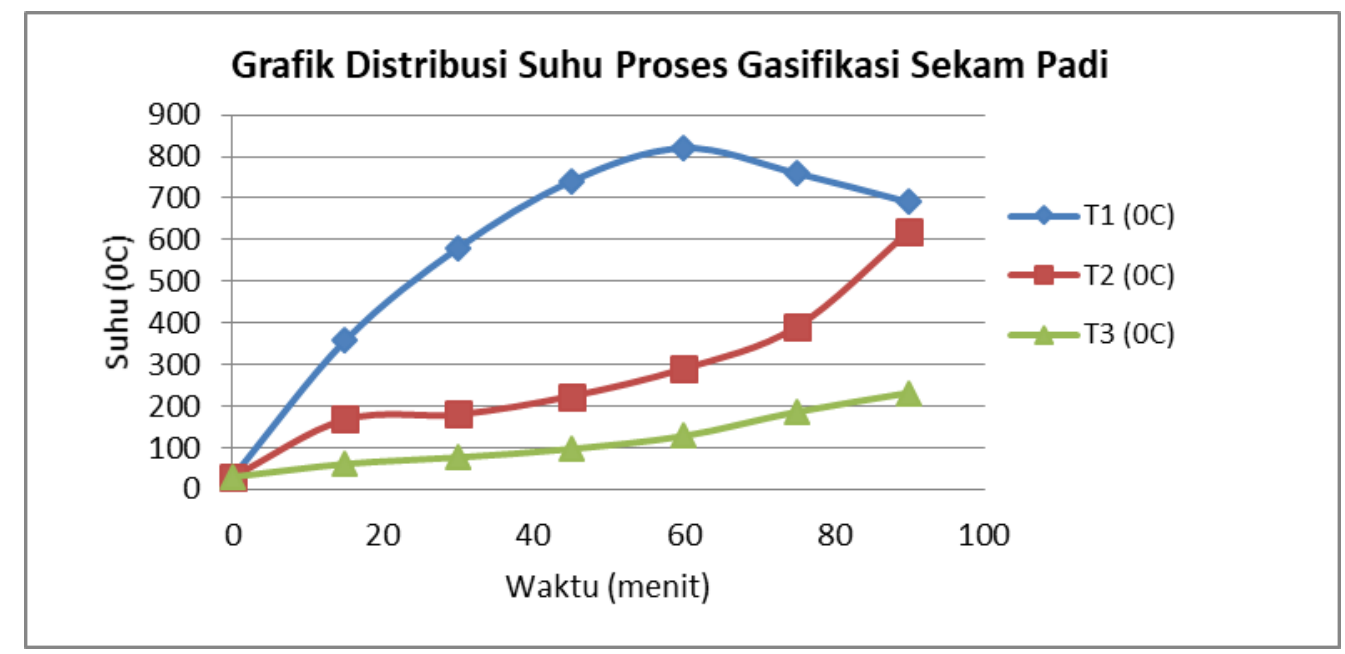

Gambar 3. Distribusi Suhu Selama Proses Gasifikasi Sekam Padi

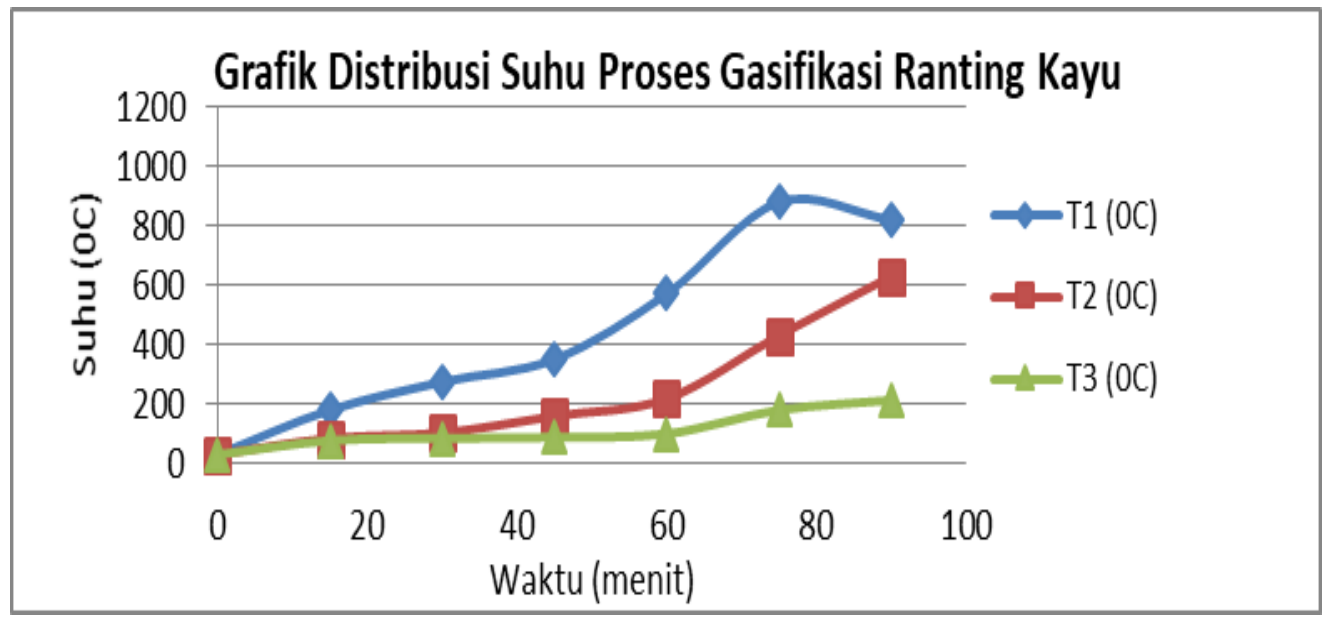

Gambar 4. Distribusi Suhu Selama Proses Gasifikasi Ranting

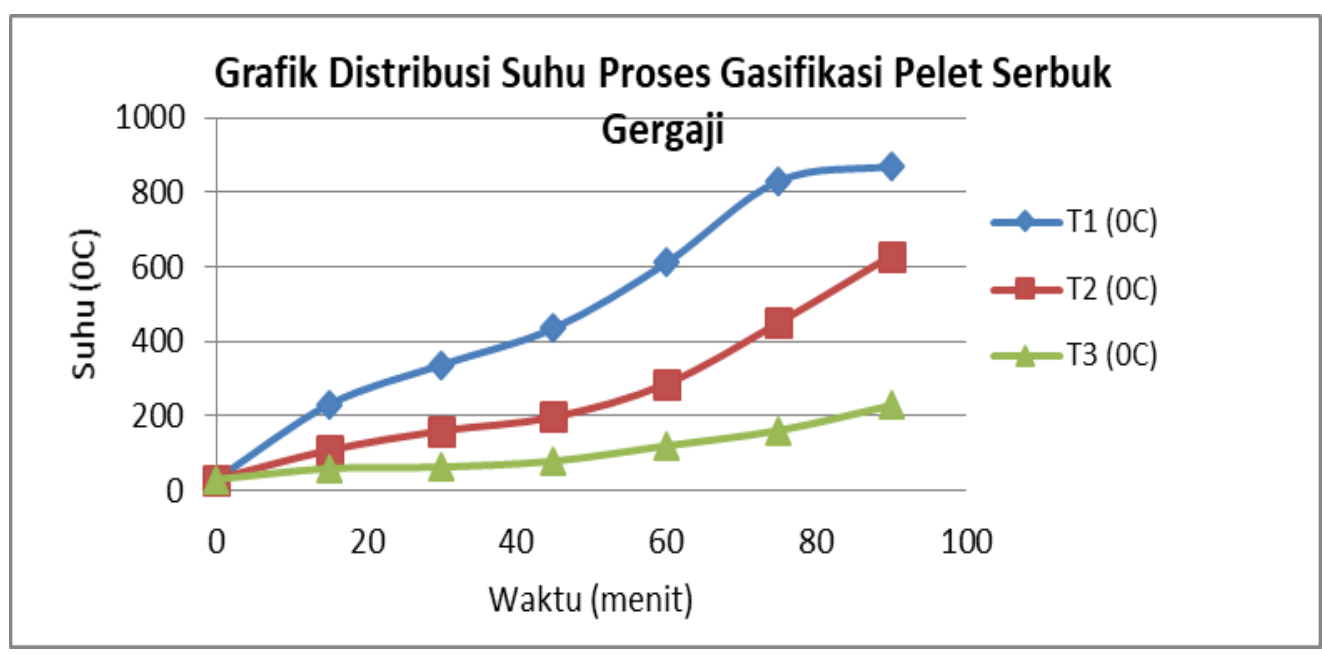

Gambar 5. Distribusi Suhu Selama Proses Gasifikasi Pelet 
Grafik distribusi suhu di atas memberikan gambaran proses yang terjadi di dalam reaktor gasifikasi. Berdasarkan Gambar 3, 4, dan 5 dapat terlihat bahwa distribusi suhu selama percobaan gasifikasi dengan berbagai macam bahan bakar menunjukkan tren yang hampir sama. Pada titik 1 pengukuran suhu $\left(\mathrm{T}_{1}\right)$, menunjukkan bahwa laju kenaikan suhu sangatlah cepat dibandingkan pada titik $2 \quad\left(\mathrm{~T}_{2}\right)$ maupun titik $3 \quad\left(\mathrm{~T}_{3}\right)$. Suhu $\mathrm{T}_{1}$ menunjukkan nilai tertinggi dan stabil untuk gasifikasi sekam padi sebesar $820^{\circ} \mathrm{C}$, ranting kayu $870^{\circ} \mathrm{C}$, dan pelet serbuk gergaji $880^{\circ} \mathrm{C}$. Hal ini menunjukkan bahwa di tempat ini $\left(\mathrm{T}_{1}\right)$ terjadi proses pembakaran (oksidasi). Sedangkan suhu di $\mathrm{T}_{2}$ menunjukkan nilai tertinggi dan stabil dalam kisaran angka tertinggi 630-690 ${ }^{\circ} \mathrm{C}$ untuk semua bahan, yang menunjukkan terjadinya prose reduksi. Sedangkan suhu di $\mathrm{T}_{3}$ menunjukkan angak tertinggi dan stabil pada kisaran nilai $213-232^{\circ} \mathrm{C}$ untuk semua bahan, sebagai tanda terjadinya proses pirolisis. Hal ini sesuai dengan referensi (Rinovianto, 2012) yang menyatakan bahwa pembakaran terjadi pada suhu antara $800^{\circ} \mathrm{C}$ sampai $1400^{\circ} \mathrm{C}$, daerah reduksi pada $600^{\circ} \mathrm{C}-900^{\circ} \mathrm{C}$, dan daerah pirolisis antara $150^{\circ} \mathrm{C}-800^{\circ} \mathrm{C}$.

\section{B. Pengaruh Jenis Bahan terhadap Suhu Proses Gasifikasi}

Untuk mengetahui pengaruh jenis bahan bakar terhadap suhu proses gasifikasi, dilakukan pengambilan data selama proses pengujian, dengan mengambil sampel pada titik $\mathrm{T}_{1}$ sebagai tempat terjadinya proses pembakaran.
Proses gasifikasi dengan bahan bakar sekam padi, memiliki laju kenaikan suhu yang lebih cepat dibandingkan dengan proses gasifikasi dengan bahan ranting kayu maupun pelet serbuk gergaji. Akan tetapi, kondisi ini bertahan hanya sampai menit ke-60, dimana suhu yang dicapai oleh proses gasifikasi sekam padi mengalami penurunan yang signifikan dibanding yang lain. Hal ini kemungkinan disebabkan karena bahan bakar sekam padi sangat mudah terbakar sehingga laju kenaikan suhu akan sangat cepat yang tentunya berakibat pada cepat habisnya bahan bakar. Setelah habisnya bahan yang mudah terbakar tersebut, suhu di titik $\mathrm{T}_{1}$ akan menurun drastis, dibandingkan percobaan dengan bahan bakar lain.

Hasil penelitian juga menunjukkan bahwa kemudahan pembakaran syn gas hasil dari proses gasifikasi juga tergantung dari jenis bahan. Untuk gasifikasi bahan sekam padi, syn gas akan mudah terbakar pada waktu 30 menit setelah alat dioperasikan, sedangkan pelet serbuk gergaji dan ranting kayu masingmasing 30 menit dan 45 menit setelah alat dioperasikan. Namun waktu nyala efektif syn gas hasil gasifikasi sekam padi, hanya 15 menit, jauh lebih pendek dibandingkan ranting kayu dan pelet serbuk gergaji yaitu 30 menit dan 45 menit.

Menurut Purwantana, dkk (2010), waktu nyala efektif gas produksi merupakan waktu yang diukur saat gas dapat dibakar secara stabil sampai gas tidak dapat menyala lagi. Waktu nyala efektif juga dapat diperoleh dengan cara mengurangi waktu operasional atau 
nyala total dengan waktu dimana gas belum atau tidak menyala. Hasil pengamatan dari tiga ulangan yang dilakukan diperoleh rerata waktu operasional sebesar 60,7 menit dengan waktu nyala efektif gas sebesar 46,3 menit dan waktu tidak efektif sebesar 14,4 menit untuk setiap $4 \mathrm{~kg}$ ampas tebu. Dengan demikian rerata waktu operasional gasifier adalah 15,2 menit/kg dengan waktu nyala efektif per $\mathrm{kg}$ ampas sebesar 11,6 menit.

\section{KESIMPULAN}

Berdasarkan hasil penelitian yang telah dilakukan, dapat diambil kesimpulan sebagai berikut:

a) Jenis bahan akan mempengaruhi distribusi suhu proses gasifikasi sampah organik. Gasifikasi dengan bahan bakar sekam padi akan menghasilkan laju kenaikan suhu yang lebih cepat dibandingkan dengan proses gasifikasi dengan bahan pelet serbuk gergaji dan ranting kayu. Akan tetapi, suhu pada gasifikasi sekam padi juga akan cepat mengalami titik puncak sehingga juga akan lebih cepat turun dibandingkan pelet serbuk gergaji dan ranting kayu.

b) Pada gasifikasi sekam padi, gas mulai terbakar setelah proses gasifikasi berjalan 15 menit sedangkan gasifikasi pelet serbuk gergaji dan ranting kayu masingmasing setelah 30 dan 45 menit setelah peralatan dioperasikan. Namun syn gas hasil gasifikasi sekam padi hanya mampu menyala selama 15 menit, jauh lebih pendek dibandingkan ranting kayu dan pelet serbuk gergaji yaitu 30 menit dan 45 menit.

\section{DAFTAR PUSTAKA}

Cahyono, M.S., (2013). Pengaruh Jenis Bahan pada Proses Pirolisis Sampah Organik menjadi Bio-Oil sebagai Sumber Energi Terbarukan. Jurnal Sains dan Teknologi Lingkungan Volume 5, Nomor 2, Juni 2013 Hal. 67-76.

Higman, C, and van der Berg, M 2003, Gasification, Elsevier Science, USA.

Pranolo, H (2010). Potensi Penerapan Teknologi Gasifikasi Tongkol Jagung Sebagai Sumber Energi Alternatif Di Pedesaan, Dalam Seminar Nasional Energi Terbarukan Indonesia di Universitas Jendral Sudirman Purwokerto.

Purwantana, B., An Nurisi, M., Markumningsih, S., (2010) Kinerja Gasifikasi Limbah Padat Tebu (Saccharum Officinarum L.) Menggunakan Gasifier Unggun Tetap Tipe Downdraft

Sudarsono, dkk (2013). Pemanfaatan Limbah Serat Pati Organik sebagai Material Komposit Poliester. Laporan penelitian hibah bersaing Institut Sains \& Teknologi AKPRIND Yogyakarta. November 2013.

Sutanto, R., Nurcahyati, Pandiatmi, P., Mulyanto, A., \& Wirawan, M. (2015). Pengaruh Laju Aliran Agent Gas pada Proses Gasifikasi Kotoran Kuda terhadap Karakteristik Syngas 
yang Dihasilkan. Proceeding Seminar Nasional Tahunan Teknik Mesin XIV (SNTTMXIV)

http://repository.ipb.ac.id/jspui/bitstr eam/123456789/40580/3/BAB\%20II _2007aga-3.pdf 